University of Nebraska - Lincoln

DigitalCommons@University of Nebraska - Lincoln

Publications from USDA-ARS / UNL Faculty

U.S. Department of Agriculture: Agricultural

Research Service, Lincoln, Nebraska

2012

Evidence of dependence between crop vigor and yield

James S. Schepers

Agricultural Research Service, james.schepers@gmail.com

Kyle H. Holland

Holland Scientific, kholland@hollandscientific.com

Follow this and additional works at: https://digitalcommons.unl.edu/usdaarsfacpub

Schepers, James S. and Holland, Kyle H., "Evidence of dependence between crop vigor and yield" (2012). Publications from USDA-ARS / UNL Faculty. 1296.

https://digitalcommons.unl.edu/usdaarsfacpub/1296

This Article is brought to you for free and open access by the U.S. Department of Agriculture: Agricultural Research Service, Lincoln, Nebraska at DigitalCommons@University of Nebraska - Lincoln. It has been accepted for inclusion in Publications from USDA-ARS / UNL Faculty by an authorized administrator of DigitalCommons@University of Nebraska - Lincoln. 


\title{
Evidence of dependence between crop vigor and yield
}

\author{
James S. Schepers • Kyle H. Holland
}

This article is a U.S. government work, and is not subject to copyright in the United States.

Published online: 26 January 2012

(C) Springer Science+Business Media, LLC (outside the USA) 2012

\begin{abstract}
A recent paper in Precision Agriculture concluded that algorithms to calculate in-season fertilizer nitrogen $(\mathrm{N})$ recommendations need to include yield and fertilizer response considerations because grain yield and yield response index are independent of each other. The authors used maximum and zero $\mathrm{N}$ yields from selected long-term wheat and maize studies to support their conclusion. Yields from plots receiving intermediate $\mathrm{N}$ rates in the maize study indicated a probable dependence between grain yield and yield response index, which is contrary to the authors' conclusions. Data from a more recent, long-term irrigated maize study on a similar soil type were used to illustrate that grain yield and yield response index are definitely dependent on each other and further that the in-season sensor-based sufficiency index is highly correlated with relative yield. The implication is that a yield component, as such, does not necessarily need to be included in development of an in-season $\mathrm{N}$ recommendation algorithm.
\end{abstract}

Keywords Nitrogen recommendations · Algorithms - Sufficiency index - Active canopy sensor

\section{Introduction}

The recent paper in Precision Agriculture by Raun et al. (2011) analyzed data from three long-term studies to conclude that yield and nitrogen $(\mathrm{N})$ fertilizer responsiveness need to be combined to calculate realistic in-season $\mathrm{N}$ rates. They based this conclusion on the fact that their data did not show a significant relationship between: (1) grain yield and the yield response index, (2) grain yield and year and, (3) yield response index and year for any of the three studies. Their approach and conclusion is troubling for several inter-related

\footnotetext{
J. S. Schepers $(\bowtie)$

USDA-ARS Collaborator, 3820 Loveland Dr., Lincoln, NE 68506, USA

e-mail: james.schepers@gmail.com

K. H. Holland

Holland Scientific, 6001 S. 58th Street, Suite D, Lincoln, NE 68516, USA

e-mail: kholland@hollandscientific.com
} 
reasons. All three studies involved long-term treatments that included a range in $\mathrm{N}$ fertilizer rates that were imposed on the same plots for either 15 years (irrigated maize study) or 40 years (wheat studies). Long-term replicated studies with zero $\mathrm{N}$ treatments (check plots) are useful to characterize the influence of $\mathrm{N}$ mineralization on crop yields, but become unrealistic to producers after several years because the check plots no longer represent situations found in typical fields. This is because residual $\mathrm{N}$ levels in soil at planting are likely to be well below levels found in producer fields and much of the mineralized $\mathrm{N}$ in the check plots has been removed in the grain. As such, early-season plant vigor is sure to be considerably different between the check plots and those that receive modest or especially high rates of $\mathrm{N}$ fertilizer. These differences in vigor throughout the growing season manifest themselves physiologically and in terms of $\mathrm{N}$ uptake, straw production and grain yield.

Raun et al. (2011) calculated a response index (RI, defined as the yield for maximum N rate divided by the yield from check plot) for the crops each year and showed a very poor or no relationship with the yield from treatments that received the maximum $\mathrm{N}$ fertilizer rate. The expression of RI used by the authors is the inverse of relative yield and contains no new information over the relative yield expression. The authors did not indicate how the check plot yields varied across years; such variations frequently attributed to differences in $\mathrm{N}$ mineralization early in the growing season and weather conditions during the grainfilling period. It seems as though the authors wanted to demonstrate that $\mathrm{N}$ responsiveness (RI) was independent of yield so they plotted the RI versus maximum yield (see Figs. 1, 2, 3 , Raun et al. 2011). The problem is that the RI type of calculation is not restricted to check plot data but rather has been applied to all $\mathrm{N}$ availability situations as Raun et al. (2001) did when they made in-season $\mathrm{N}$ recommendations. As $\mathrm{N}$ rates approach the maximum rate, the RI values approach 1.0. So what can be learned when maximum yield is plotted as a function of RI for all $\mathrm{N}$ rates, including the check plots? The complete data set for Mead, Nebraska, USA (from the files of the late Professor Robert Olson) in Raun et al. (2011) showed that the first fertilizer $\mathrm{N}$ application rate of $101 \mathrm{~kg} / \mathrm{ha}$ was nearly adequate to achieve maximum yield for a given year (Fig. 1) and thus offered little opportunity to explore the relationship between $\mathrm{N}$ rate and yield responsiveness. However, a comparison of annual relative yields across years shows that climate and mineralization influenced

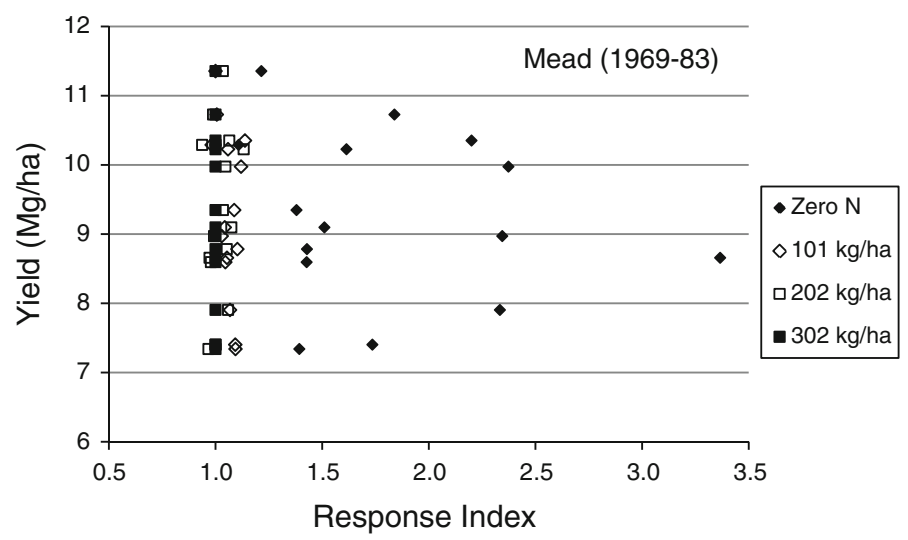

Fig. 1 Maximum yield as a function of the yield-based response index (yield at $302 \mathrm{~kg} \mathrm{~N} / \mathrm{ha} / \mathrm{yield}$ at given $\mathrm{N}$ rate) for maize at Mead, NE, USA (1969-1983) for long-term plots receiving several fertilizer $\mathrm{N}$ rates 


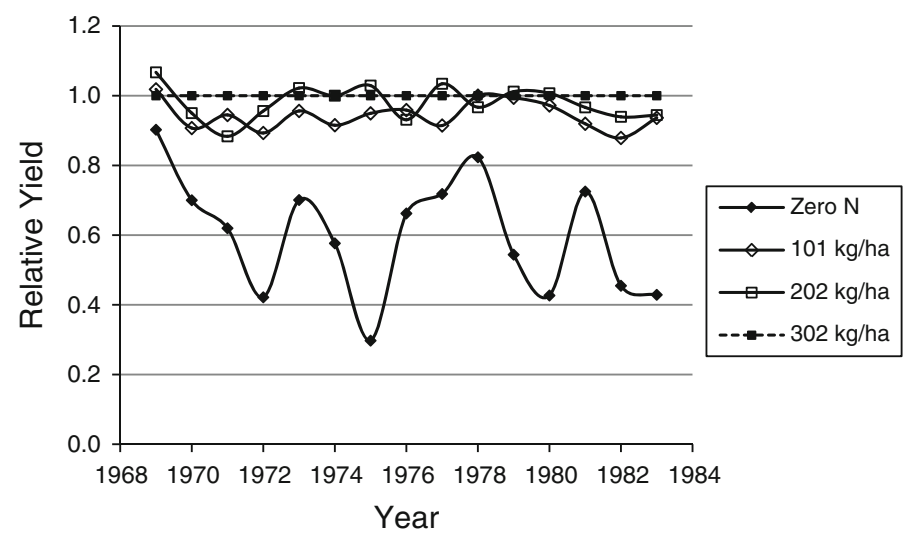

Fig. 2 The effect of year on relative yield of irrigated maize at Mead, NE, USA, receiving different fertilizer $\mathrm{N}$ rates

check plot yields more than those that received a modest to high rate of $\mathrm{N}$ fertilizer (Fig. 2).

When relative yields for each year were compared to the normalized mean yield for plots receiving the highest $\mathrm{N}$ rate across the 15 years of the study, they showed no obvious trend between check plot relative yield and the relative yield $\left(r^{2}=0.04\right)$ for a given year (Fig. 3). The yield variability across years for plots receiving the highest $\mathrm{N}$ rate had a CV of $13 \%$, but $34 \%$ for the check plots. Bear in mind that this study was furrow irrigated and the variability in yields under rain-fed conditions would be expected to be somewhat greater. Years with favorable growing seasons (i.e. high relative yields) frequently showed high relative yields for the check plots but the opposite was true for some years, clearly illustrating the importance of $\mathrm{N}$ availability to establish vigorous plants early in the growing season. Further, trends and relationships demonstrated in Figs. 1, 2, and 3 illustrate why it is inappropriate to make management decisions and fertilizer $\mathrm{N}$ recommendations based on anything related to data gleaned from long-term check plots. The value of such plots is to provide unique information about the interactions between weather and $\mathrm{N}$ mineralization as evaluated through crop yields.

It would be far more appropriate to evaluate the relationship between RI and the maximum yield using $\mathrm{N}$-rate studies with more $\mathrm{N}$ rates in the responsive range than available to Raun et al. (2011) in the Mead, Nebraska study. To benefit producers the most, such N-rate studies should be conducted on a new site each year without excessive carryover of residual $\mathrm{N}$. Uncertainties related to residual $\mathrm{N}$ carry-over frequently lead to N-rate treatments being superimposed on the same plots year-after-year. This approach provides considerably more control in terms of ending up with a range in soil $\mathrm{N}$ availability from which to evaluate crop responsiveness to fertilizer. Data from a more recent long-term study near Shelton, Nebraska, USA are offered to illustrate the short-comings of drawing conclusions from studies that are not appropriate to evaluate given relationships. Figure 4 was generated from data collected in 2002-2004 and illustrates a strong relationship between RI and yield for both continuous maize and maize after soybeans. This data included the mean of four hybrids with four replications. Plots had received the same $\mathrm{N}$-rate treatments $(0,50,100,150$ and $200 \mathrm{~kg} \mathrm{~N} / \mathrm{ha})$ since 1991 . The source of irrigation water used after 1996 contained $<1 \mathrm{mg} \mathrm{NO} \mathrm{NO}_{3}-\mathrm{N} / \mathrm{l}$. The three lowest data points were 


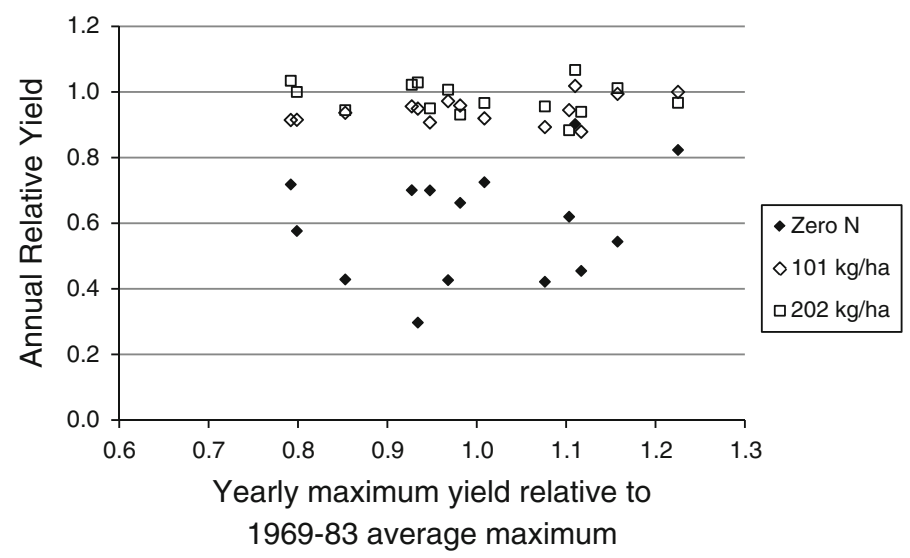

Fig. 3 Relative yield within a year as affected by fertilizer $\mathrm{N}$ rate in relation to relative yield across all years of an irrigated maize study at Mead, NE, USA (1969-1983)

derived from plots that had not received any $\mathrm{N}$ fertilizer for more than a decade. As such, these points would not be found in producer fields. Note that the maize yields after soybeans followed the same trend as for continuous maize (Fig. 4). To some extent, the strong relationship is expected because the "yield" values appear in data contained within both the $X$ and $Y$ axes. With this consideration alone, it is invalid to conclude that yield and $\mathrm{N}$ responsiveness are independent.

Differences in yield responsiveness to $\mathrm{N}$ fertilizer between years can be attributed to many factors. Therefore, data from a single year should probably provide the best test of the relationship between RI and yield while minimizing the influence of weather. Figure 5 only represents data from 2009 for a single hybrid in the same long-term study at Shelton, Nebraska, USA, but with eight replications for plots receiving 0, 50, 100, 150 and $200 \mathrm{~kg} \mathrm{~N} / \mathrm{ha}$ at planting (maize-after-maize). Note that the 2002-2004 (Fig. 4) and 2009 data (Fig. 5) followed similar trends. As might be expected, the check plot yields in 2009

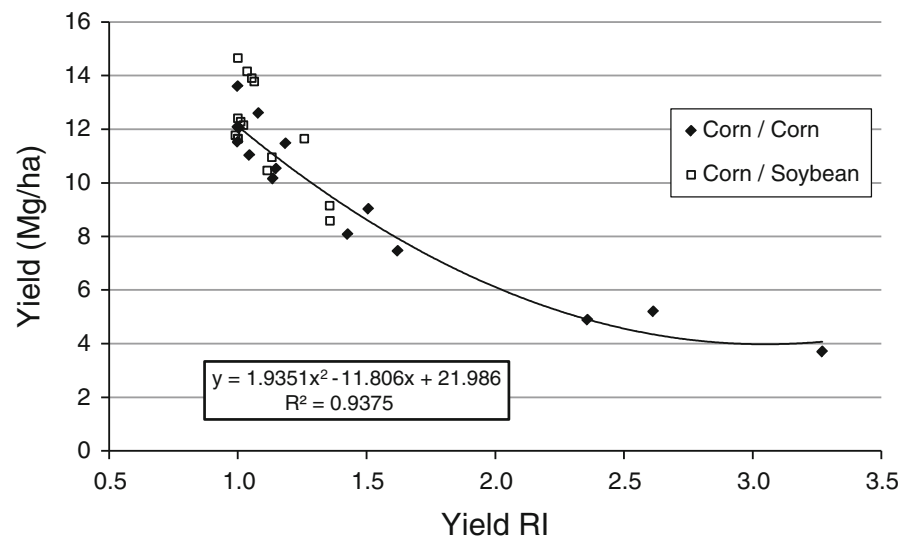

Fig. 4 The relationship between yield response index (RI) and the maximum yield attained with the highest fertilizer N rate at Shelton, NE, USA in 2002-2004. Yield RI (response index for yield) = (yield from highest $\mathrm{N}$ rate)/(yield at other $\mathrm{N}$ rates). Regression line is for maize after maize 


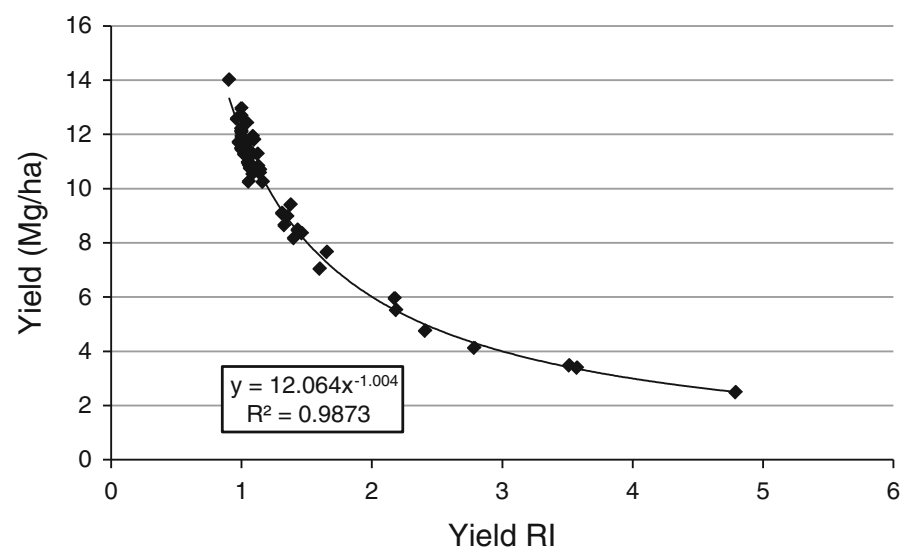

Fig. 5 Relationship between yield response index (RI) and maximum yield of one irrigated maize hybrid in 2009 fertilized at five fertilizer $\mathrm{N}$ rates at Shelton, NE, USA

were lower than 5 years earlier. Figures 4 and 5 illustrate that the RI versus yield relationship is a continuum rather than being two independent parameters as proposed by Raun et al. (2011). This being the case, there is no need to include a yield component term in the calculation of an in-season fertilizer $\mathrm{N}$ recommendation. The data presented by Raun et al. (2011) are not representative of farmer fields because no $\mathrm{N}$ was applied to the same plots for many years which do not represent the range of situations intended for in-season $\mathrm{N}$ applications. The logic behind only using check plot data in their figures cannot be rationalized other than to justify the need to include "yield" in the way they calculated the need for additional $\mathrm{N}$ fertilizer. Perhaps there are other considerations that are not obvious and not disclosed in their paper?

Although the paper by Raun et al. (2011) only deals with yield data, the implications of their conclusions carry over to their justification for the need to predict yield potential, which involves sensor-based, in-season RI values (Raun et al. 2001). The numerical value that they assign to RI is related to the crop sufficiency index (SI, defined as the vegetation index of plants in question divided by the vegetation index of reference plants with adequate $\mathrm{N}$ ) through a yield potential prediction equation. Again, it should be pointed out the RI is a modeling preference and does not provide any additional information to SI. Therefore, it is appropriate to explore how sensor SI values are related to yield. The following three figures relate chlorophyll index values (converted to SI values) collected at the 12-leaf stage (V12, see Ritchie et al. 1997; BBCH stage 42, see Lancashire et al. 1991) with Crop Circle 470 active crop canopy sensors (Holland Scientific, Lincoln, NE, USA) to various yield parameters. Note the strong relationship between sensor SI data and the SI concept applied to yield data (linear $r^{2}=0.90$ ) (Fig. 6), which is the premise for using in-season canopy sensor measurements to assess the need for determining how much additional fertilizer $\mathrm{N}$ should be applied. Figure 6 only involves one hybrid with eight replications in two field strips with plots that were fertilized at $0,50,100,150$ and $200 \mathrm{~kg} /$ ha as a planting time application. At the V9 growth stage (BBCH stage 39), the linear $r^{2}$ value was 0.81 between SI and relative yield for the same study. Since the sensors measure chlorophyll status and biomass, the relationship should be nearly linear, because, at some point, other plant growth factors besides $\mathrm{N}$ limit the production of chlorophyll and the generation of plant biomass. The 2009 yield data were transformed to generate an RI value 


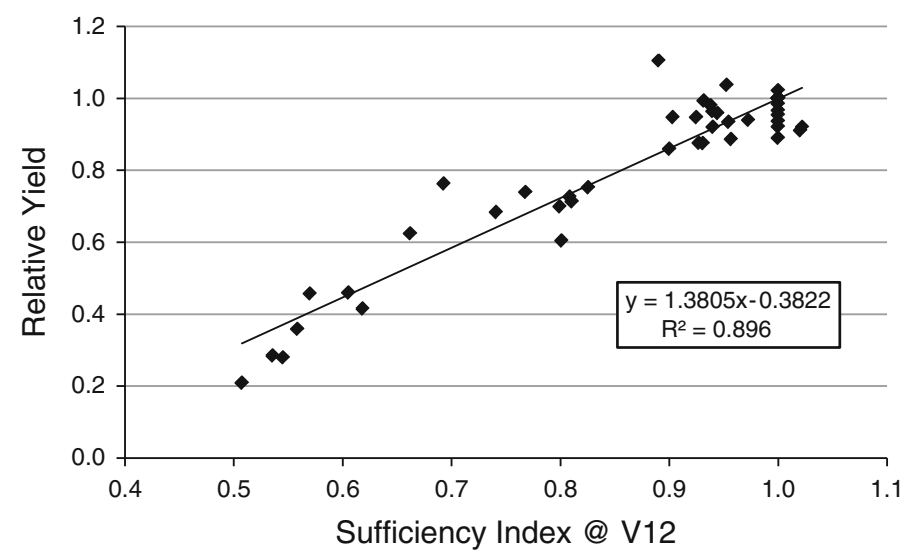

Fig. 6 Relationship between relative yield and crop sufficiency index (SI) determined at the V12 growth stage of irrigated maize grown at five fertilizer N rates at Shelton, NE, USA in 2009

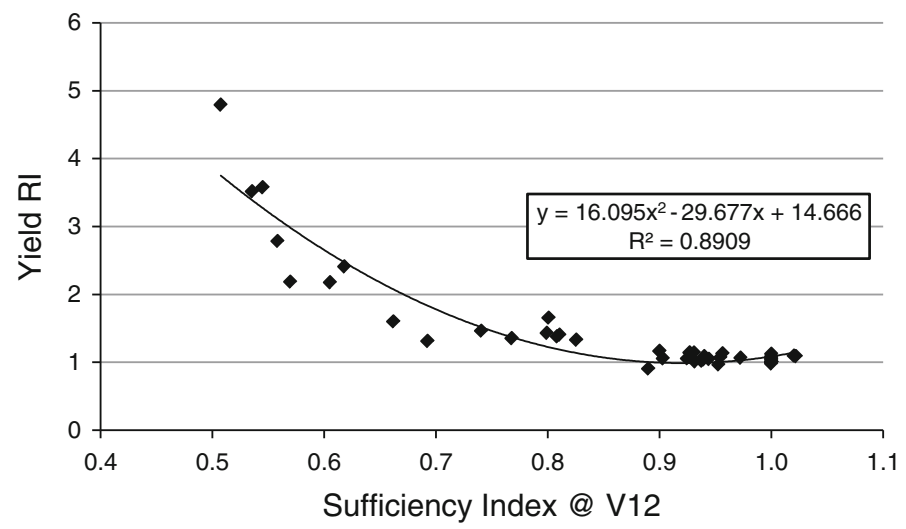

Fig. 7 Relationship between the response index (RI) generated from yield data and in-season sensor-based sufficiency index (SI) values (red-edge chlorophyll vegetation index approach) for a single irrigated maize hybrid grown at five $\mathrm{N}$ rates at Shelton, NE, USA in 2009

as proposed by Raun et al. (2011). The resulting relationship in Fig. 7 is strong but not linear as in Fig. 6.

The strong linkage between in-season crop vigor measurements and yield is illustrated in Fig. 8. The relationship only represents one field and 1 year, but this is the kind of relationship that is important to the producer that manages this field. This post mortem analysis generated a significant mathematical expression that would change from year to year because maximum yields can vary by $25 \%$ or more because of weather conditions. It should be noted that strong relationships as illustrated in Figs. 6 and 8 hardly require incorporating a yield component when making in-season fertilizer $\mathrm{N}$ recommendations based on crop sensor data as proposed by Raun et al. (2011). Even though Fig. 6 only represents 1 year, one hybrid and one location, it is this kind of relationship that makes it possible to directly use in-season canopy sensor data to recommend the need for additional $\mathrm{N}$ fertilizer. This all means that it is not necessary to estimate yield potential and back- 


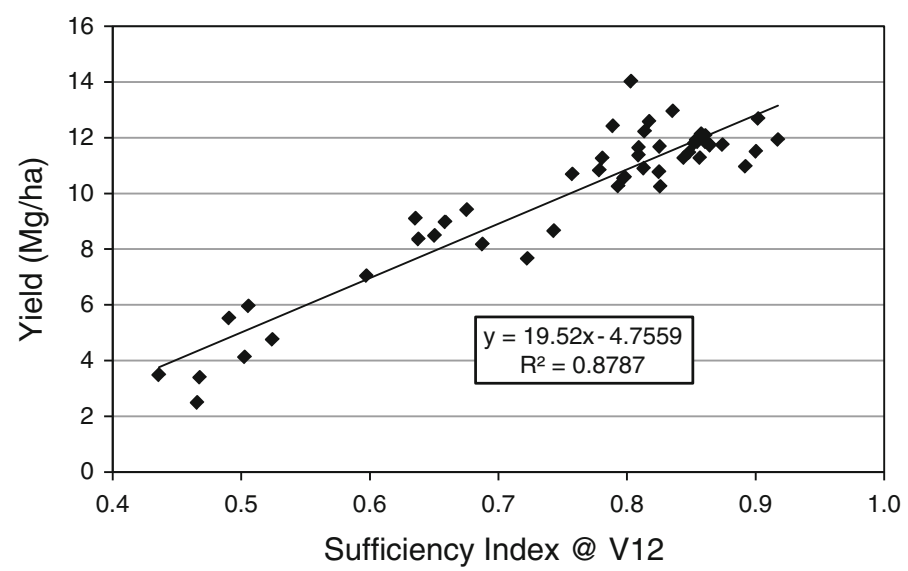

Fig. 8 Relationship between crop-sensor based sufficiency index (SI) values at the V12 growth stage of a single irrigated maize hybrid and yield at Shelton, NE, USA in 2009

calculate the need for additional $\mathrm{N}$ because relative yield is generally highly correlated with in-season SI values. Absolute yield cannot be predicted with certainty but Fig. 6 illustrates that in-season SI values are highly correlated with relative yield under irrigated conditions. The challenge is to convert the sensor-based SI values into reliable fertilizer $\mathrm{N}$ rate recommendations. Producer experiences in terms of the $\mathrm{N}$ rate required to achieve optimum yields are a good place to start because their experiences integrate factors like $\mathrm{N}$ mineralization and $\mathrm{N}$ losses for each field. It is interesting to note that not many farmers base their $\mathrm{N}$ application rates on the possibility of a good growing season because they know that $\mathrm{N}$ mineralization works with them and will supply additional plant-available $\mathrm{N}$ if growing conditions are conducive.

Raun et al. (2011) used literature citations by Bray (1962) to challenge the sufficiency concept when dealing with $\mathrm{N}$ because the most prominent inorganic form (nitrate) is soluble in water and mobile in soil. Their argument is based on the observation that soil nitrate levels can range from adequate to excessive early in the growing season but become strongly deficient at later growth stages. In contrast, immobile nutrients that are deemed to be sufficient via soil testing before planting are not likely to be deficient at harvest. To help put this difference in perspective, consider that $\mathrm{N}$ and $\mathrm{K}$ accumulation in maize is similar at harvest but the soil test levels for nitrate-N at planting might range from 5 to $50 \mathrm{mg} / \mathrm{l}$ while a $\mathrm{K}$ concentration $>200 \mathrm{mg} / \mathrm{l}$ is usually considered to be adequate to excessive. Translating these concentrations to the surface $300 \mathrm{~mm}$ of soil puts the residual $\mathrm{N}$ (nitrate plus ammonium) level at $\sim 20-200 \mathrm{~kg} / \mathrm{ha}$ and the quantity of $\mathrm{K}$ at $\sim 800 \mathrm{~kg} / \mathrm{ha}$. Additional $\mathrm{N}$ is required in most cases to grow a healthy crop of maize but only $\sim 25 \%$ of the available $\mathrm{K}$ is taken up by a $12-13 \mathrm{Mg} / \mathrm{ha}$ maize crop and $\sim 80 \%$ of the $\mathrm{K}$ in the crop biomass is returned to the soil via the residues.

It should be noted that both soil sampling and plant tissue testing are point-in-time measurements. The argument that the sufficiency concept cannot be extended from the soil environment to above-ground plant tissue is without merit because analytical labs typically evaluate nutrient concentrations in plant tissues in terms of being deficient, low, sufficient or high. The adequacy scale changes with growth stage in recognition of crop nutrient needs and the distribution within plants. Indexing plant nutrient concentrations to healthy plant concentrations effectively removes any discussion about critical concentrations. As 
such, normalized SI values are automatically adjusted for weather, growth stage, cropping history, cultivar, etc. As noted in Fig. 8, in-season SI values are highly correlated with yield, but this is a post mortem analysis. Mullen et al. (2003) noted a similarly strong relationship with wheat, but for some reason the co-authors are perpetuating the notion that yield and yield responsiveness are necessary components when making in-season $\mathrm{N}$ recommendations. Currently, the two methods for real-time $\mathrm{N}$ applications based on canopy sensor data require:

(1) incorporating a farmer's $\mathrm{N}$ response observations (i.e. producer's optimum $\mathrm{N}$ rate) for a specific field into the algorithm as proposed by Holland and Schepers (2010) or,

(2) predicting potential yield based on current-year sensor data that is applied to previous observations of yield and canopy sensor readings that have been adjusted for growing-degree days (or the like) for multiple fields in a region. This approach was developed for wheat and amounts to determining the early season growth rate between planting and sensing and then correlating that growth rate with yield at harvest, which amounts to projecting the early-season growth rate until harvest to predict potential yield.

As such, farmers making sensor-based in-season nutrient applications have two options related to the aforementioned methods. These options are:

(1) make intelligent estimates of the optimum $\mathrm{N}$ rate for a given field based on recent experiences and current growing conditions, or

(2) assume that a given field will respond similarly to how other fields in the region have responded to fertilizer $\mathrm{N}$ in the past even though climate, soils and inherent fertility levels were probably different.

\section{Conclusions}

Selected data provided by Raun et al. (2011) prompted them to conclude that yield and the yield response function were independent of each other. Including all fertilizer $\mathrm{N}$ rates in the analysis of their long-term irrigated maize study indicated a probable dependence between these parameters. Data from a 1991-2009 study with irrigated maize on a similar soil showed a definite dependence between these parameters across four hybrids over a 3 -year period and an even stronger relationship within a year for a single hybrid. The implications of their conclusions, which are being challenged, are far-reaching for precision agriculture because they are using them to support the necessity to predict yield potential when making in-season variable-rate $\mathrm{N}$ applications. Other widely accepted approaches rely on the strong dependence between in-season canopy sensor information (sufficiency index) and relative yield and do not include a component for estimated yield potential which, in itself, is considered to be unreliable by many because of weather uncertainties and soil differences.

\section{References}

Bray, R. H. (1962). Confirmation of nutrient mobility concept of soil-plant relationships. Soil Science, 86, $124-130$.

Holland, K. H., \& Schepers, J. S. (2010). Derivation of a variable rate nitrogen application model for inseason fertilization of corn. Agronomy Journal, 102, 1415-1424. 
Lancashire, P. D., Bleiholder, H., Langeluddecke, P., Stauss, R., van den Boom, T., Weber, E., et al. (1991). A uniform decimal code for growth stages of crops and weeds. Annals of Applied Biology, 119, 561-601.

Mullen, R. W., Freeman, K. W., Raun, W. R., Johnson, G. V., Stone, M. L., \& Solie, J. B. (2003). Identifying an in-season response index and the potential to increase wheat yield with nitrogen. Agronomy Journal, 95, 347-351.

Raun, W. R., Solie, J. B., \& Stone, M. L. (2011). Independence of yield potential and crop nitrogen response. Precision Agriculture, 12, 508-518.

Raun, W. R., Solie, J. B., Stone, M. L., Johnson, G. V., Lukina, E. V., Thomason, W. E., et al. (2001). In-season prediction of yield potential using wheat canopy reflectance. Agronomy Journal, 93, $131-138$.

Ritchie, S. W., Hanway, J. J., \& Benson, G. O. (1997). How a corn plant develops. Special Publication 48. Iowa State University of Science and Technology Cooperative Extension Service. Ames, IA, USA. 